\title{
O DEBATE DA QUALIDADE DE VIDA COMO INSTRUMENTO DE DEMOCRATIZAÇÃO DO LAZER NO ESPAÇO URBANO ${ }^{1}$
}

Recebido em: 10/12/2018

Aceito em: 23/08/2019

\author{
Isabela Veloso Lopes Versiani ${ }^{2}$ \\ Universidade Estadual de Montes Claros (UNIMONTES) \\ Montes Claros - MG - Brasil
}

RESUMO: Embora se verifique uma constante associação do lazer com a temática da qualidade de vida e questões urbanas, um aprofundamento direto dessas relações ainda é escasso. Assim, o presente artigo, de escopo teórico, propõe reflexões na direção de uma maior aproximação dessas duas áreas, buscando contribuir para uma inserção/legitimação do lazer nas discussões urbanas a partir de sua compreensão vinculada ao paradigma da qualidade de vida urbana em construção, sobretudo no sentido de colaborar para o direcionamento de ações de planejamento urbano e políticas públicas específicas para sua maior democratização. Dentre os resultados, verifica-se que uma maior aproximação do campo do lazer a esse novo paradigma reafirma a importância dos espaços públicos como meio para se ampliar o acesso às vivências de lazer nas cidades, essenciais na composição do direito à cidade e à qualidade de vida em sua totalidade.

PALAVRAS CHAVE: Qualidade de Vida. Atividades de Lazer. Espaços Públicos.

\section{THE DEBATE ABOUT QUALITY OF LIFE AS AN INSTRUMENT FOR THE DEMOCRATIZATION OF LEISURE IN URBAN SPACE}

ABSTRACT: Although there is a constant association of leisure with the theme of quality of life and urban issues, a directly and deepening investigation of these relations is still scarce. Thereby, this article, with a theoretical scope, proposes reflections towards a closer approximation of these two areas, seeking to contribute to an insertion / legitimation of leisure in urban discussions based on their understanding linked to the paradigm of urban quality of life under construction, especially in the sense of collaborating in the direction of urban planning actions and specific public policies for its greater democratization. Among

1 A discussão aqui apresentada integra parte da Dissertação de Mestrado intitulada Lazer E Qualidade De Vida Urbana: análise a partir da distribuição de equipamentos públicos para vivência físico-esportiva, sob orientação do Prof. Dr. Antônio Dimas Cardoso e Co-orientação da Profa. Dra. Anete Marília Pereira, pelo Programa de Pós-Graduação em Desenvolvimento Social. Bolsista de Mestrado FAPEMIG no período. Revista e ampliada para submissão à Licere.

${ }^{2}$ Docente da Universidade Estadual de Montes Claros (UNIMONTES). 
the results, it is verified that a closer approximation of the leisure field to this new paradigm, reaffirms the importance of public spaces as an instrument to expand access to leisure experiences in cities, essential in the composition of the right to the city and quality of life in its totality.

KEYWORDS: Quality of Life. Leisure Activities. Public Spaces.

\section{Introdução}

A compreensão do espaço urbano como efeito da articulação de múltiplas relações e práticas que movimentam a sociedade gera conflitos que se evidenciam, principalmente, na desigual ocupação e uso do solo urbano; e na contradição entre a produção socializada do espaço e sua apropriação privada ou entre seu valor de uso e seu valor de troca, reflexo da regulação das trocas de mercadorias do capitalismo na dimensão territorial, com desdobramentos também no campo do lazer.

Nessa lógica, tem-se como consequência a supervalorização da rentabilidade econômica na reprodução do capital, com ausências e ineficiências no campo dos meios de consumo coletivo (dos meios de transporte aos grandes equipamentos da cidade moderna) (LOJKINE, 1997) o que compromete a promoção de melhores condições de vida no âmbito urbano, especialmente dos mais pobres, já que a realização de necessidades e seus impactos nas condições de vida da população não se revelam da mesma forma para todos.

Agravada por um processo crescente de segregação espacial e aumento das desigualdades no acesso à infraestrutura urbana e a equipamentos coletivos essenciais, essas contradições manifestam-se por uma maior ou menor "socialização" e/ou “privatização" das relações urbanas, com reflexos e impactos na qualidade de vida. 
Para se buscar modificar esse quadro, é importante considerar a análise do espaço urbano também como palco privilegiado para transformação dessas crescentes contradições, vinculando-o essencialmente a uma posição política, em que os papéis do Estado (Poder Público) e das reivindicações sociais no urbano assumem centralidade no debate necessário para promover mudanças.

Uma compreensão de cidade vinculada à dimensão social e política das contradições que moldam o cotidiano urbano torna-se fundamental para pensar e implementar formas de melhoria da qualidade de vida de seus habitantes e ampliar a cidadania no planejamento urbano. A referência à cidadania na configuração das cidades aproxima a leitura do espaço urbano à dimensão política de sua produção que passa, por um lado, pelo entendimento da influência da lógica capitalista nas ações do Estado e no direcionamento de políticas urbanas e, por outro, pela resistência contraposta dos movimentos sociais e conformação de novas lutas urbanas (LOJIKNE, 1997; VÉRAS, 2000; CASTELLS, 2006).

Dessa forma, a dimensão política do espaço urbano também pode ser lugar da luta por demandas que atendam a necessidades básicas da população, numa perspectiva contrahegemônica, a partir de múltiplas determinações sociais na configuração do urbano no cotidiano, que o transforma em espaço de resistência e socialização, de residência e convivência, de mobilidade e liberdade, de oportunidades e acesso a equipamentos urbanos, de realização dos direitos sociais; enfim, da esfera do consumo coletivo dos bens e meios que são essenciais à melhoria da qualidade de vida de qualquer cidadão.

Para Lefèbvre (2008), a impossibilidade do urbano para todos só pode ser superada através da prática social e de uma urbanização crítica, fazendo retornar o valor do uso para 
além do valor da troca e, assim, promover a realização da vida urbana, que não elimina o confronto e a luta, mas, pelo contrário, enseja uma nova produção social do espaço em busca do direito à cidade, ou seja, o direito à vida urbana, condição de um humanismo e de uma democracia renovados.

A contra-hegemonia da dimensão política no urbano, amparada pelas crescentes reivindicações coletivas, tem ensejado processos de reformas e mudanças, mesmo que lentas, na direção de novos modelos de desenvolvimento urbano que priorizam o espaço do viver e, consequentemente, resultam em novas configurações sociais desse quadro. Tal processo perpassa a produção do espaço aliada à prática social, preocupada com o atendimento das especificidades e necessidades da população através de um planejamento urbano participativo, em detrimento de uma produção material do espaço apoiada no planejamento urbano tecnicista.

Com reflexos no contexto urbano brasileiro, principalmente a partir das diretrizes e instrumentos promulgados pelo Estatuto da Cidade (BRASIL, 2001), essas influências têm proporcionado novos debates acerca da questão urbana no país e de alternativas para solucionar suas contradições, problemas e impasses no campo da política urbana, passando a exigir a redefinição de espaços, novas práticas de cidadania e reformulações de políticas públicas específicas no direcionamento das ações de planejamento.

Nessa regulamentação, o direito à cidade é visto a partir de uma dimensão ampla, legitimado pelo direito de uso e ocupação do solo urbano, ao saneamento básico, à infraestrutura urbana, aos serviços públicos, ao acesso ao mercado de trabalho, ao lazer, entre outros, integrado a mecanismos sociais de incremento da qualidade de vida (BRASIL, 2001). 
Assim, a qualidade de vida tem sido um tema emergente que interfere no presente e futuro das cidades e, como um campo recente de estudos aplicado ao urbano, tem contribuído para o fortalecimento do debate acerca de um maior desenvolvimento social nas cidades, inclusive por meio de uma maior aproximação do lazer como um de seus aspectos essenciais.

O campo de estudos do lazer, nas últimas décadas, tem se desenvolvido como uma área multidisciplinar que contempla diversos temas, dentre eles, aspectos ligados à sua compreensão como um fenômeno social e sua dimensão cultural; os elementos necessários à sua delimitação conceitual; os conteúdos culturais envolvidos em suas práticas; seu campo de formação e atuação profissional; seu entendimento como um direito social e os desdobramentos dessa perspectiva no desenvolvimento de políticas públicas específicas, entre outros.

Nessas discussões, o lazer estabelece relações com a promoção da qualidade de vida em diferentes perspectivas, porém, nem sempre essa associação aparece de forma aprofundada ou relacionada diretamente ao meio urbano. A partir de uma pesquisa exploratória breve, verifica-se que o que predomina na discussão teórica, quando esta aparece de forma sistematizada, é o reconhecimento do lazer como campo importante à melhoria da qualidade de vida ora associado a sua dimensão vinculada ao bem-estar e à promoção da saúde, proporcionados pela atividade física como prática de lazer, em maior número; ora vinculado à busca do desenvolvimento humano e da cidadania de forma geral.

Como exemplos dessa primeira vertente, mais ligada ao bem-estar e à saúde, o trabalho de Markus Nahas (2006), Atividade Física, Saúde e Qualidade de Vida, é referência no que tange a conceitos e sugestões para a construção de um estilo de vida 
ativo. Outro trabalho nessa linha foi a publicação organizada por Roberto Vilarta (2004), Qualidade de vida e politicas públicas: saúde, lazer e atividade fisica, a partir de um debate intersetorial sobre formas de implantação de políticas públicas de saúde integradas ao campo do lazer para melhoria da qualidade de vida e maior interação entre família, comunidade e sociedade.

Como expoente da segunda vertente, destaca-se o trabalho de Castellani Filho (1996), Lazer e Qualidade de Vida, em que se reconhece o lazer como um dos elementos indicadores da qualidade de vida de um povo, mas que, no conjunto da discussão dos entraves à realização de um desenvolvimento humano no contexto mundial e nacional, sua vivência é influenciada pelo incremento de ações no universo das iniciativas privadas e pela dificuldade do Estado em promover um lazer comunitário. Outro trabalho é a proposta de Cláudia Bonalume (2002), O lazer numa proposta de desenvolvimento voltada à qualidade de vida, que problematiza acerca da busca pela qualidade de vida e da compreensão do lazer nesse processo, que é diretamente influenciado pela dicotomia desenvolvimento econômico e social.

Também a Revista Licere, em seu segundo volume, traz uma coletânea de artigos com o tema Lazer, Qualidade de Vida e Cidadania, com destaque para dois desses, os quais apontam interações entre essas três áreas na busca pela dignidade humana e possibilidade de desenvolvimento comunitário (MORAIS, 1999); e maior aproximação do lazer a princípios relativos à cidadania na construção do sentido de pertencimento associado à possibilidade de vivência e construção da liberdade, e necessidade de superação e inversão da noção da qualidade de vida como um modismo contemporâneo, fortemente associado ao consumo e a busca de soluções individuais para os problemas sociais, pelo 
sentido de uma "vida de qualidade", na direção da experiência humana como um processo e não como um produto (LINHALES, 1999).

No campo empírico e na direção de uma maior aproximação com as questões urbanas, estudos mais recentes com a participação de Simone Rechia, no campo da Educação Física, a exemplo do artigo Espaços Públicos de Lazer na promoção da qualidade de vida: uma revisão integrativa (SILVA et al, 2013); ou relatos de pesquisas em contextos específicos de outras áreas do conhecimento como o de Oliveira e Mascaró (2007), da Engenharia e Arquitetura, sobre a Análise da Qualidade de Vida urbana sob a ótica dos espaços públicos de lazer, na cidade de Passo Fundo; ou Silva (2012) com o trabalho Lazer, Espaço Público e Qualidade de Vida na capital Potiguar, da Geografia, dentre outros, têm produzido reflexões que aproximam o lazer e seus espaços públicos do tema da qualidade de vida no meio urbano.

Assim, observa-se que o lazer tem se inserido como uma dimensão essencial da qualidade de vida em diferentes aspectos, inclusive na relação com questões diretamente ligadas à configuração urbana, além de constatar-se, também, sua inserção no debate mais atual dos novos direcionamentos da Política Urbana no Brasil, como parte integrante do direito à cidade. Embora se verifique uma constante associação do lazer com questões urbanas específicas e com a temática da qualidade de vida no urbano, um maior aprofundamento direto dessas relações ainda é escasso no debate acadêmico das principais áreas que discorrem sobre tais questões.

Dessa forma, o presente artigo, de escopo teórico, propõe reflexões na direção de uma maior aproximação dessas duas áreas, buscando contribuir para uma maior inserção/legitimação do lazer nas discussões urbanas e para compreensão de algumas 
relações que podem ser estabelecidas entre o lazer e o paradigma da qualidade de vida urbana em construção, sobretudo no sentido de auxiliar o direcionamento de ações para o planejamento urbano e políticas públicas específicas para sua maior democratização.

A partir de pesquisa bibliográfica, o artigo está estruturado em duas partes. No primeiro momento, procura-se apontar caminhos na direção de uma construção teóricoconceitual para a qualidade de vida urbana, que a legitime como um novo paradigma no direcionamento do planejamento urbano e evidencie suas potencialidades para promover mudanças na forma como o desenvolvimento urbano tem se configurado nas cidades. $\mathrm{Na}$ sequência, busca-se uma aproximação desse novo paradigma ao campo do lazer, sobretudo na relação com os espaços públicos e sua importância como meio para se garantir um maior acesso às suas vivências nas cidades, reafirmando o lazer como um direito social que compõe o direito à cidade e à qualidade de vida em sua totalidade.

\section{A Qualidade de Vida como Paradigma para Outro Desenvolvimento Urbano}

Em função de sua complexidade, definir o termo qualidade de vida coloca-se como um desafio particular, pois abrange diferentes abordagens e problemáticas. A expressão qualidade de vida não é nova, mas a sistematização da área enquanto campo de pesquisa em sua totalidade pode ser considerada um fenômeno recente, especialmente no âmbito urbano.

Inicialmente vinculada ao campo da saúde (YUAN; YUEN; LOW, 1999), nos últimos anos, essa expressão ganhou cada vez mais relevância em outros campos de pesquisa e, particularmente, no campo do desenvolvimento, envolvendo a dimensão econômica, ambiental, social e urbana, e contemplando aspectos individuais, coletivos, materiais, imateriais, objetivos e subjetivos. 
Embora a preocupação com a qualidade de vida tenha se incorporado em alguns discursos políticos e sociais a partir da década de 1960, no bojo do modelo economicista predominante, foi a busca pela elevação do Produto Interno Bruto (PIB) per capita que se impôs como referência nas décadas seguintes e superou a discussão da necessidade de mudanças quantitativas e qualitativas na forma como as questões relativas às condições de vida vinham sendo tratadas, principalmente das populações pobres.

Recentemente, com o agravamento dos problemas propiciados por esse modelo, a temática da qualidade de vida voltou a ganhar destaque, vinculada, principalmente, à dimensão ambiental e social no contexto urbano. Muitos estudos e pesquisas passaram a problematizar seu conceito e sua repercussão em relação a essas áreas, sendo consenso notar a complexidade envolvida na delimitação de seus principais aspectos.

De fato, definir qualidade de vida não é uma tarefa simples, sobretudo se levarmos em consideração sua dimensão individual, pessoal e subjetiva - vinculada às diferentes percepções, valores, necessidades e desejos relacionados em uma mesma situação - que variam segundo condições culturais, temporais e espaciais diferenciadas. Só por essa constatação, discutir qualidade de vida, para se chegar a um denominador único, seria uma tarefa praticamente impossível.

Por expressar uma área multidisciplinar do conhecimento, a qualidade de vida irá constituir-se em uma temática complexa, que envolve elementos do cotidiano do ser humano, sendo tomada como expressão de dimensões ligadas à construção de um estilo de vida, modo de vida ou condições de vida das pessoas que, no senso comum, tem incorporado uma visão positiva em relação a esses termos, mesmo sendo difícil estabelecer definições claras acerca de seus aspectos. 
Um primeiro passo, para maior delimitação, é compreender que a qualidade de vida está diretamente associada a uma melhoria no bem-estar das pessoas, tanto no plano individual quanto coletivo e, nesse sentido, segundo Marques (2007), não pode ser analisada como algo a ser alcançado que depende exclusivamente da atitude individual do sujeito em mudar seus hábitos, mas deve centrar-se na busca por alternativas para a melhoria do nível de vida do maior número de pessoas possível, e isso não depende só do sujeito, embora os meios de comunicação e o mercado se apropriem cada vez mais desse discurso para promover produtos e convencer a população que, ao adquiri-los, também estão "adquirindo" uma maior "qualidade de vida" ${ }^{3}$.

Como forma de buscar sistematizar esse universo, a construção da compreensão da qualidade de vida tem se desenvolvido com referências, concepções, construção de indicadores e procedimentos metodológicos vinculados a dois campos principais: o que envolve aspectos objetivos e o dos aspectos subjetivos. Para Marques (2007, p.23):

Pontos de vista objetivos buscam uma análise ou compreensão da realidade pautada em elementos quantificáveis e concretos, que podem ser transformados pela ação humana. A análise desses elementos considera fatores como alimentação, moradia, acesso à saúde, emprego, saneamento básico, educação, transporte, ou seja, necessidades de garantia de sobrevivência próprias da sociedade contemporânea. Essa perspectiva se caracteriza como uma busca por dados quantitativos e qualitativos que permitem traçar um perfil de um indivíduo ou grupo em relação ao seu acesso a bens e serviços [...]. Com esse tipo de tratamento, torna-se possível estabelecer quadros de perfis socioeconômicos para ações

\footnotetext{
3 Para Marques (2007), esse discurso é muito corrente em ambientes comerciais, propagandas de alimentos e condomínios residenciais. Semelhante a esse uso pode ser, também, a associação da qualidade de vida à construção ideológica presente no city-marketing promovido em algumas cidades. Segundo Souza (2008, p. 303), algumas vezes o city-marketing pode não se constituir como um instrumento informativo confiável nas cidades por encontrar-se "deformado", "resultado da tentativa de influenciar não apenas investidores e turistas em potencial, mas toda uma opinião pública, formando uma imagem de cidade conforme aos interesses e à visão de mundo de grupos dominantes", que nem sempre corresponde à realidade, pois busca um discurso que esconde suas mazelas sociais.
} 
voltadas à melhoria da Qualidade de Vida para os sujeitos envolvidos. A análise da Qualidade de Vida sob um aspecto subjetivo também leva em conta questões de ordem concreta, porém, considera variáveis históricas, sociais, culturais e de interpretação individual sobre as condições de bens materiais e serviços do sujeito. Não busca uma caracterização dos níveis de vida apenas sobre dados objetivos, mas relaciona-os com fatores subjetivos como emocionais, expectativas e possibilidades dos indivíduos ou grupos em relação às suas realizações, e a percepção que os atores têm de suas próprias vidas, considerando, inclusive, questões imensuráveis como prazer, felicidade, angústia e tristeza.

A ênfase aqui conferida à esfera objetiva da qualidade de vida, assim como de seus instrumentos e indicadores, não desconsidera a importância da esfera subjetiva nesse processo. Embora essas duas dimensões sejam complementares e difíceis de serem analisadas separadamente, a opção por priorizar a discussão com referência à percepção da qualidade de vida mais próxima de seus aspectos objetivos justifica-se pelas enormes dificuldades que nosso país tem em oferecer acesso integral da população aos bens e serviços que compõem esse campo, principalmente na dimensão dos bens de consumo coletivo. De acordo com Marques (2007, p. 29), a compreensão acerca da esfera objetiva é importante em dois aspectos:

1) Como instrumento de avaliação das condições de vida das populações, indicando carências de serviços ou de assistência; 2) Como base para caracterização dos grupos em relação aos ambientes socioeconômicos em que estão inseridos. Considerando que a percepção de Qualidade de Vida do ser humano é vinculada tanto às suas subjetividades, quanto às possibilidades de realização do mesmo em sua vida, essa esfera de percepção se caracteriza como um primeiro passo para o entendimento desse campo de conhecimento.

A partir desse recorte, a busca por uma sistematização teórica e empírica acerca do conceito de qualidade de vida tem tido desdobramentos significativos no campo do 
desenvolvimento, principalmente quando vinculada à satisfação de necessidades humanas fundamentais e seus reflexos para expansão de um modelo que priorize as capacidades humanas, que contribua para a conquista de uma maior autonomia dos indivíduos e que amplie a cidadania.

Uma contribuição nesse aspecto foi relacionar o conceito de qualidade de vida com a satisfação das necessidades humanas - amplamente disseminado pelas experiências Social-Democratas Escandinavas na década de 1970 - que influenciou perspectivas e ações no sentido de compreender o bem-estar social e individual a partir de três verbos considerados básicos à existência humana: ter, amar e ser.

Essas três áreas foram definidas como princípios para a formulação de indicadores sociais, em que a esfera do ter (having) seria a das necessidades materiais e impessoais fundamentais para a sobrevivência e para evitar a miséria, com indicadores relacionados a recursos econômicos, condições de habitação, emprego, saúde e educação; a esfera do amar (loving) seria a das necessidades sociais, centrada nas relações com outras pessoas e formações de identidades sociais; e a esfera do ser (being) seria a das necessidades relativas ao crescimento pessoal, retratada por processos de integração com a sociedade e harmonização com a natureza, atividades coletivas, atividades políticas, oportunidades de lazer, entre outras (ALLARDT, 1993, p. 89-91).

Segundo Claudette Vitte (2002), a importância da experiência escandinava nas discussões sobre a qualidade de vida liga-se, fundamentalmente, às questões políticas no debate sobre bem-estar, na qual a dimensão da participação dos indivíduos nas decisões políticas e atividades coletivas influenciam a vida de todo cidadão, sendo as políticas públicas um importante instrumento para focalizar os graus de desigualdade social 
existentes entre os diversos grupos sociais e impor patamares mínimos de bem-estar a serem assegurados coletivamente.

Ainda vinculada à discussão das necessidades humanas, outra reflexão foi colocada pelo economista Amartya Sen (1993), que traçou a relação entre desenvolvimento e qualidade de vida a partir de aspectos valorativos, éticos e morais em meio ao processo. Crítico da compreensão do desenvolvimento restrito ao crescimento econômico, Sen destaca que o fim último do desenvolvimento deve ser a própria vida humana, sendo o aumento do PIB e da renda per capita importantes apenas como meios para se atingir qualidade de vida.

Na perspectiva de Sen (1993), o desenvolvimento não deve ser vinculado somente à focalização de bens e de utilidade, mas ser definido em relação àquilo que os seres humanos podem fazer ou ser através de um conjunto de efetivações/funcionalidades humanas (functionings) e da expansão das capacidades (capabilities) em desempenhar essas efetivações, tanto em níveis elementares quanto complexos.

Assim, Herculano (1998) destaca que a qualidade de vida, na perspectiva de Sen, pode ser avaliada em termos de capacitação para alcançar funcionalidades. A capacitação de uma pessoa dependerá de um conjunto de fatores, incluindo-se aí características de personalidade, mas será influenciada, principalmente, pelos arranjos sociais, sendo que a intenção do autor - através do uso do termo capacitação - é a de enfatizar a análise política e social das privações.

A capacitação não se mede pelas realizações efetivas de uma pessoa, mas pelo conjunto de oportunidades reais que ela tem em seu favor. A qualidade de vida não deve, portanto, ser entendida como um mero 
conjunto de bens, confortos e serviços, mas, através destes, das oportunidades efetivas das quais as pessoas dispõem para ser. Oportunidades dadas pelas realizações coletivas, passadas e presentes (HERCULANO, 1998, p.7).

Apesar da discussão sobre qualidade de vida ser influenciada por diversos aspectos, inclusive subjetivos, a compreensão de sua associação à efetivação de oportunidades e escolhas pelos indivíduos, através de realizações coletivas, a aproxima de uma posição política que, no contexto urbano, reflete-se nos direcionamentos para ações de planejamento urbano e políticas públicas que contribuam para sua melhoria e ampliação, em estreita ligação com seus aspectos objetivos.

Essa perspectiva recente é enfatizada por Herculano (1998) pela sua possibilidade em tornar o conceito de qualidade de vida um instrumental sociológico, um novo campo não só de estudos, mas de intervenção, definido pelo estudo substantivo, descritivo e normativo das condições de vida social, econômica e ambiental. O conceito de qualidade de vida é então explicitado como:

[...] a soma das condições econômicas, ambientais, científico-culturais e políticas coletivamente construídas e postas à disposição dos indivíduos para que estes possam realizar suas potencialidades: inclui a acessibilidade à produção e ao consumo, aos meios para produzir cultura, ciência e arte, bem como pressupõe a existência de mecanismos de comunicação, de informação, de participação e de influência nos destinos coletivos, através da gestão territorial que assegure água e ar limpo, higidez ambiental, equipamentos coletivos urbanos, alimentos saudáveis e a disponibilidade de espaços naturais amenos urbanos, bem como a preservação de ecossistemas naturais (HERCULANO, 1998, p. 17).

Efetivar essas condições nas cidades para que seus habitantes possam realizar suas potencialidades e atingir uma maior qualidade de vida tem sido cada vez mais difícil. As 
diferenças marcantes e constitutivas de espaços segregados nas cidades brasileiras distanciam esse conceito de uma dimensão realmente cidadã no urbano.

A cidade deveria ser o lugar de efetivação de direitos e deveres, o lugar do cidadão, onde "os sinais de cidadania, da igualdade de condições, de acessos, de direitos e deveres comuns a todos deveriam estar inscritos por toda a parte e ser reconhecidos em todos os pontos, mas não é necessariamente o que acontece" (SANTANA, 2000 apud VITTE, C. 2009, p.99). Muitas vezes, o que se vê nas cidades é justamente o contrário: à cidadania contrapõe-se a exclusão com suas múltiplas adjetivações refletida, sobretudo, no acesso ao consumo de bens coletivos. Diante dessa realidade, assegurar o direito a uma vida com mais qualidade restringe-se ao consumo individual de bens e condições materiais de uma minoria da população.

É justamente nesse ponto que Claudete Vitte (2002) retoma a importância da política em ocupar lugar central na discussão sobre o presente e futuro das cidades e da cidadania como ação coletiva, afirmativa e cotidiana na construção e efetivação de direitos, dando centralidade à questão social no debate sobre políticas de intervenção no espaço urbano e práticas de planejamento urbano na atualidade. Para a mesma autora, a discussão sobre qualidade de vida passa a ser uma das premissas norteadoras do desenvolvimento e do bem-estar, devendo ser considerada como um direito de cidadania.

Nessa perspectiva, outra importante contribuição é dada por Souza (2008), para quem uma das tarefas ao se lidar com o planejamento e a gestão urbanos como pesquisa social aplicada é a de integrar a reflexão sobre aquilo que, sinteticamente, deve ser a finalidade do planejamento e da gestão - o desenvolvimento urbano, ou a mudança social positiva da e na cidade. 
Para Souza (2008), o desenvolvimento urbano é entendido como desenvolvimento socioespacial pensado a partir de dois pilares complementares: um aumento da justiça social e uma maior qualidade de vida, enfatizando a busca por maior autonomia individual e coletiva das pessoas como determinante desse processo, e uma análise que contemple não só as relações sociais, mas, igualmente, a espacialidade na discussão.

Entre justiça social e qualidade de vida deve ser enxergada uma relação de complementariedade essencial: qualquer dos dois, se tomando isoladamente e sem o outro, é insuficiente para servir de base para avaliações e estratégias de desenvolvimento sócio-espacial; cada um dos dois calibra e complementa o outro. Sem a consideração da exigência de justiça social, falar em qualidade de vida cada vez melhor para um número cada vez maior de pessoas pode, perfeitamente, mascarar a permanência ou mesmo o aumento de desigualdades gritantes de acesso aos recursos e meios de satisfação de necessidades, ainda que o patamar geral se eleve para a maioria ou mesmo para todos (SOUZA, 2008, p.72).

Embora a discussão da qualidade de vida possa ser influenciada por uma série de definições e aspectos, será com referência à promoção de uma maior justiça social e efetivação da cidadania que se compreende sua interface no âmbito urbano e se busca resgatar a centralidade na dimensão social para um verdadeiro desenvolvimento urbano.

A partir dessa visão, no trato de discussões teórico-metodológicas acerca da qualidade de vida e sua relação com o planejamento e gestão urbanos, partilha-se da ideia colocada por Claudete Vitte e Tânia Keinert (2009, p.10) de que, embora a análise da qualidade de vida possa se legitimar no debate por sua dimensão individual e, mais recentemente, subjetiva, opta-se por concentrar esforços no avanço da análise da dimensão política da qualidade de vida, que "envolve aspectos relativos ao planejamento e às práticas 
de gestão pública, à democracia, ao fortalecimento da cidadania, à luta e garantia dos direitos fundamentais da pessoa, bem como dos direitos sociais" no espaço urbano.

A qualidade de vida urbana, dessa forma, passa a ser apreendida não apenas em nível pessoal ou de uma dimensão individual e subjetiva, mas vincula-se diretamente à sua dimensão coletiva. Levando-se em conta o grau de adequação das características espaciais, ambientais e sociais da cidade às metas, planos e aspirações dos indivíduos, o que deverá ser priorizado é a ligação da qualidade de vida com o desenvolvimento urbano no sentido de aproximá-la ao cotidiano de seus habitantes, com o objetivo de efetivar suas capacidades e ampliar suas possibilidades de escolhas em um ambiente urbano mais justo, humano, cidadão e ambientalmente sustentável. Segundo Nahas, a qualidade de vida urbana será, então, "uma expressão que abrange o conceito de qualidade de vida e também o de qualidade ambiental, mas, além disto, será o conceito espacialmente localizado, reportandose ao meio urbano, às cidades" (NAHAS, 2009, p.126).

Dada a ênfase na dimensão política, a qualidade de vida urbana legitima a preocupação com questões que interferem diretamente nas condições de vida e bem-estar da população urbana, abarcando áreas que envolvem não só aspectos econômicos, mas também, sociais, ambientais, de cidadania, de serviços urbanos, de habitação, de mobilidade e transporte, de segurança, de educação, de saúde, de lazer, entre outros.

Assim, a melhoria da qualidade de vida da população tem ligação direta com o atendimento de demandas sociais e várias têm sido as tentativas de construção de instrumentos para sua mensuração no âmbito urbano. Através de sistemas de indicadores de qualidade de vida urbana, muitas cidades, por iniciativa de seus gestores públicos ou 
organizações da sociedade civil, buscam inserir essa temática no desenvolvimento de ações estratégicas para o direcionamento do planejamento e políticas públicas relacionadas a

diversas áreas, principalmente através de diagnósticos de desigualdades intraurbanas ${ }^{4}$.

Esses sistemas, em essência, se desenvolvem com base em metodologias preocupadas em construir diferentes indicadores para comparar regiões de uma mesma cidade, redes de cidades ou países, com o objetivo de aprimorar técnicas de mensuração e compartilhar experiências no âmbito do planejamento urbano e das políticas públicas que dependem do real conhecimento dos problemas a serem enfrentados para sua eficácia.

A contribuição desses indicadores de qualidade de vida urbana para conhecer melhor a realidade social mostra-se como um tema emergente e extremamente relevante, principalmente quando associado ao modelo de planejamento urbano preconizado pelas diretrizes do Estatuto da Cidade, o que legitima, no nível empírico, a discussão da qualidade de vida como um novo paradigma para direcionar e potencializar o debate e as ações do planejamento na direção de outro desenvolvimento urbano, tão necessário no contexto brasileiro, e que pode contribuir de forma significativa para legitimação e aproximação do lazer às questões urbanas, especialmente na relação com seus espaços públicos nas cidades, a ser aprofundada no tópico seguinte.

\footnotetext{
${ }^{4}$ Embora não seja objetivo desse artigo aprofundar a análise na construção metodológica desses sistemas de indicadores, existem muitos exemplos disponíveis no contexto internacional e nacional, tais como as analisadas de forma mais específica na dissertação de origem deste artigo: Global City Indicators; The Quality of Life Project - da Nova Zelândia; Sistema de Monitorização da Qualidade de Vida Urbana de Porto; Programa Bogotá Como Vámos; Índice de Qualidade de Vida Urbana - IQVU de Belo Horizonte; Rede Nossa São Paulo.
} 


\section{Lazer e Qualidade de Vida Urbana: Aproximações e Potencialidades para Democratização de seus Espaços}

Quando analisado em interface com o âmbito urbano, assim como existem diferentes abordagens para o delineamento do estudo das cidades, também o campo de estudos do lazer pode ter influência de diversas áreas do conhecimento, dialogando com a História, a Antropologia, a Sociologia, a Educação Física, entre outras, e, inclusive, pode se desenvolver sob influência de um referencial marxista, aqui destacado, o que aproxima a compreensão do lazer a ser desenvolvida, em interface com a qualidade de vida e o espaço urbano, de muitas questões já apontadas.

Para Padilha (2006, p.12), entender o lazer a partir da abordagem marxista pressupõe, entre outras características, ver que a sociedade não é harmônica, mas permeada por contradições e conflitos, formada por classes sociais distintas, cujas condições materiais determinam, não só a existência, mas também a forma de lazer de cada classe, em que "não há o mesmo lazer para todos, ainda mais porque, na sociedade capitalista, tudo é potencialmente transformado em mercadoria, inclusive o lazer que passa a ser comprado e vendido no mercado".

Assim, para proceder à inserção do lazer no debate sobre qualidade de vida é importante ressaltar dois pontos. No primeiro, identifica-se a necessidade de superação da vigente compreensão do lazer somente como mercadoria, que tem reflexos nas práticas e, sobretudo, nos espaços de lazer nas cidades (lazer enquanto bem de consumo individual). No segundo, discute-se a emergência de uma perspectiva contra-hegemônica, com a ampliação do conceito de lazer a partir de seu entendimento como um direito social (lazer enquanto bem de consumo coletivo). 
Inicialmente, é relevante, ainda, expor que, nesse artigo, parte-se da compreensão do lazer entendido como um fenômeno moderno, que se desenvolveu em estreita relação com o processo de industrialização no contexto urbano ${ }^{5}$. Tal processo foi responsável pela geração de mudanças e transformações na produção e no cotidiano, influenciadas diretamente pelos interesses das classes dominantes, detentoras dos meios produtivos e do domínio do capital, com reflexos em todas as esferas da vida social.

Desse modo, o surgimento do lazer esteve ligado às transformações advindas da Revolução Industrial, principalmente através da organização do trabalho nas fábricas, da luta e conquista dos operários pela redução da jornada de trabalho, e da necessidade de controle das elites burguesas desse tempo de não-trabalho conquistado, porém restrito ao que será considerado lícito ${ }^{6}$.

Apesar de surgir em meio às reivindicações presentes na luta dos trabalhadores pela redução da jornada de trabalho, a institucionalização do lazer não foi arquitetada diretamente pelos seus próprios beneficiários. Ao contrário, surgiu como uma apropriação desse tempo "livre", não pelos trabalhadores, mas pelos interesses econômicos e hegemônicos das elites capitalistas, que passaram a influenciar suas práticas e

\footnotetext{
5 Existem diversas teorias acerca da origem do lazer, inseridas no tempo e a partir das relações humanas que são nele construídas. Segundo Gomes (2004), partindo-se das dúvidas e controvérsias que marcam os estudiosos do assunto, a indagação principal quanto à origem do lazer seria a de identificar se esse fenômeno sempre existiu, com ocorrência datada desde a Antiguidade Clássica, ou se ele é representado como um fenômeno típico das modernas sociedades urbano-industriais.

${ }^{6}$ Como no início da Idade Moderna o ócio era visto como algo pejorativo e perigoso (exemplificado pelo alcoolismo, jogos de azar e outros vícios), resultado da incorporação dos valores protestantes à construção do discurso pela burguesia de sua compreensão como um mal à sociedade - tanto para os trabalhadores quanto para o sistema capitalista - o lazer surge como mecanismo de controle sobre o "tempo livre" dos operários, que, segundo Gomes (2006, p.175), incorporou em seu significado etimológico a ideia de uso desse tempo para atividades saudáveis, uma vez que, a palavra lazer "é proveniente do latim licere/licet, termos criados pela antiga civilização romana com o significado de lícito, permitido, poder, ter o direito".
} 
características, apesar da busca constante por sua ressignificação e maior emancipação no campo das lutas políticas, numa perspectiva contra-hegemônica ${ }^{7}$.

Nessa direção, o entendimento conceitual de lazer que se associa à qualidade de vida não é o mesmo do seu surgimento. Ao partir de uma perspectiva contra-hegemônica que, segundo Mascarenhas (2000), pressupõe uma transformação social, base para uma nova cidadania, o conceito de lazer será construído através da noção de liberdade, responsabilidade, participação e organização política. Dessa forma, a concepção de lazer, compartilhada nesse artigo, o compreende como:

[...] um fenômeno tipicamente moderno, resultante das tensões entre capital e trabalho, que se materializa como um tempo e espaço de vivências lúdicas, lugar de organização da cultura, perpassando por relações de hegemonia. Desta forma, dentro de uma perspectiva crítica e de emancipação dos grupos populares, o lazer pode ser entendido também como tempo e espaço para o exercício da cidadania e prática da liberdade (MASCARENHAS, 2000, p.58).

Apesar desse direcionamento conceitual, quando se considera a interação do lazer com a sociedade capitalista atual e sua complexidade, o lazer enquanto exercício da cidadania e prática da liberdade ainda está distante de se materializar no espaço das relações cotidianas, sobretudo no âmbito urbano, e longe de proporcionar, através de uma vivência crítica de sua prática, mais qualidade de vida, embora se encontre algumas práticas

7 Nesse sentido, é importante reconhecer que esse tempo disponível não é tão "livre" assim. Segundo Gomes (1998), se esse tempo assumir como funções básicas apenas a compensação de frustrações ou recuperação das energias para o exercício laboral, desprovido de crítica ou reflexão, contribuirá apenas para a manutenção da estrutura social vigente através de uma prática alienada [principalmente quando associada a um consumo desenfreado]. Por outro lado, é preciso que essas experiências de lazer sejam vivenciadas como oportunidades de reconquista de valores perdidos na extenuante situação de exploração, que compreende o lazer sob uma outra ótica, configurando-o como um instrumento de luta, resistência, de organização coletiva e como possibilidade de desenvolver a liberdade e a felicidade. 
de resistência em contextos específicos ${ }^{8}$.

Compreendido como um fenômeno social dentro de um processo capitalista em constante transformação, o lazer tem sido influenciado pelas transformações das relações de trabalho, agravadas pela precarização e intensificação da exploração da força de trabalho (NAVARRO, 2006), e pelo predomínio da lógica capitalista em interface com o mercado em suas práticas e manifestações, entendido apenas como mais uma mercadoria do mundo contemporâneo.

No contexto urbano, a interação desse lazer com a vida social, com as características da cidade e com os espaços disponíveis para sua prática problematiza sua vivência a partir da desigualdade de condições materiais ao seu consumo, da difículdade de acesso a suas práticas, enfim, das oportunidades escassas que o meio urbano oferece para o desenvolvimento de outro tipo de lazer para a grande maioria da população.

Diante desse quadro, um importante instrumento de combate à precarização das próprias vivências de lazer foi a intensificação de sua discussão, especialmente após a Segunda Guerra Mundial, como um direito social, integrante do exercício da cidadania e da busca por mais qualidade de vida, passando a estar presente em importantes documentos ${ }^{9}$.

Apesar desse movimento, o direito ao lazer no Brasil, embora previsto na Constituição Federal (BRASIL, 1988) e na maioria das Constituições Estaduais e Leis Orgânicas Municipais - ao lado de outros direitos sociais como a educação, a saúde, o

${ }^{8}$ Como exemplo, cita-se a pesquisa etnográfica realizada por José Guilherme Magnani (2003), Festa no Pedaço: cultura popular e lazer na cidade, na qual o autor busca compreender a importância do lazer na vida diária da população de bairros periféricos e das diferentes formas de desfrutá-lo, abrindo o caminho para muitos outros estudos nessa linha.

${ }_{9}$ Destaca-se, aqui, o lazer como um direito humano, legitimado pela Declaração Universal dos Direitos Humanos, Artigo XXIV (ONU, 1948). 
trabalho, a moradia, a segurança, a previdência social - e considerado um instrumento para desenvolver valores e alcançar cidadania, na realidade enfrenta muitas dificuldades para ser considerado de fato um direito social presente e legitimado nas cidades brasileiras.

Ser assegurado juridicamente não é sinônimo de que o lazer seja garantido como um direito social e de que tenha sua prática democratizada, ainda mais em função da situação de pobreza de parte significativa da população, que sem alcançar condições básicas de sobrevivência e existência, coloca a concretização do direito ao lazer em segundo plano, o que contribui, de maneira geral, para que essa área seja uma das menos desenvolvidas nas administrações públicas brasileiras (MUNHOZ, 2008).

A prevalência dessa visão cria dificuldades para sua reivindicação, inclusive no âmbito estatal. Marcellino (2007) analisa que o lazer tem adquirido uma posição inferior em relação aos outros direitos sociais, subordinado a uma "hierarquia de necessidades" que só prejudica sua legitimidade e possibilidades. Os reflexos negativos daí decorrentes são facilmente constatados nas deficientes políticas públicas do setor. Para completar esse quadro, o lazer ainda é visto de modo pejorativo por muitas pessoas, relacionado à preguiça, ao desperdício de tempo e à improdutividade, e não relacionado à sua dimensão como um fator de desenvolvimento social, que contribui para a busca de uma formação integral do ser humano e para a melhoria da qualidade de vida no conjunto da sociedade ${ }^{10}$.

Outra dificuldade é que o próprio campo de sistematização do esporte e do lazer no desenho institucional do Estado e a sua agenda de responsabilidades ora aparecem como

${ }^{10}$ Embora haja sinais de um processo inverso de valorização das práticas de lazer na mídia, vinculada, sobretudo, a sua dimensão mercadológica e, também, quando se aprofunda sua discussão no cotidiano dos grupos urbanos. Outro fato importante é a presença constante do tema do lazer nas experiências de Orçamento Participativo nas cidades, que prioriza a participação popular na composição do orçamento municipal, elegendo-se por meio deste as principais demandas de cada região da cidade. 
setores vinculados à educação, cultura, turismo, juventude, meio ambiente etc., ora como um setor de estrutura e institucionalidade próprias, com formatos variados (secretarias, subsecretarias, diretorias, coordenadorias e gerências), o que evidencia a fragilidade no processo de consolidação da área e de suas políticas públicas (LINHALES et al, 2008).

Para se tentar mudar essa realidade na área de acesso ao lazer, Saldanha Filho (2003) enfatiza o papel que as políticas públicas assumem, compreendidas como construções participativas de uma coletividade que visam à garantia dos direitos sociais dos cidadãos. Apesar dos conflitos, ações e contradições que formam os processos de consolidação do direito ao lazer através de suas políticas públicas específicas, é no seio destas que se têm buscado desenvolver o lazer e também o esporte, visando a uma maior democratização de suas práticas e a ampliação de suas dimensões na construção da cidadania $^{11}$.

A atuação do Estado brasileiro nas questões referentes ao lazer, na esfera nacional, com desdobramentos na estadual e municipal, pode ser mais bem explicitada através das finalidades e ações desempenhadas pelo Ministério do Esporte, instituído em 2003, que é responsável pela construção de uma Política Nacional de Esporte e Lazer, e tem como missão formular e implementar políticas públicas inclusivas e de afirmação do esporte e do lazer como direitos sociais dos cidadãos, colaborando para o desenvolvimento nacional e humano.

11 O sentido dessa democratização deve estar ligado à superação de uma prática funcionalista ou assistencialista das atividades de lazer. Deve promover o lazer como uma "questão de cidadania, de participação cultural", que considere seus aspectos sociais, educativos, e "revolucionários" (MARCELLINO, 1996). 
Através da realização de Conferências Nacionais de Esporte (2004, 2006, 2010), o Ministério do Esporte tem discutido e implementado ações através de programas de governo específicos para democratizar a prática do lazer, principalmente com relação à temática de seus espaços. Dentre essas ações, propõe-se a realização de diagnósticos acerca da estrutura esportiva e de lazer para ações articuladas entre os diversos níveis da administração pública e também de uma articulação com a iniciativa privada e organizações da sociedade civil, com o objetivo de construir, modernizar, revitalizar, preservar, otimizar e maximizar os espaços e equipamentos para o esporte e o lazer com segurança e qualidade, visando aos interesses e às necessidades da população (BRASIL, 2004).

Além disso, registra-se, nessas conferências, a importância da desconcentração dos espaços e equipamentos públicos e privados como medidas para priorizar o acesso de comunidades com populações em situação de vulnerabilidade ou exclusão social e do papel atribuído ao regime de colaboração entre União, estados e municípios, com ênfase na municipalização para a consolidação do esporte e do lazer como direitos sociais, valorizando a acessibilidade, descentralização, intersetorialidade e multidisciplinaridade das ações esportivas e de lazer (BRASIL, 2006).

No aprofundamento da questão das políticas públicas locais destinadas a esse setor, Saldanha Filho (2003) considera que, na maioria das cidades, quem gesta as políticas de esporte e lazer é a Secretaria de Esporte e Lazer. Segundo o autor, são muitos os problemas de implantação dessas políticas. Além das dificuldades financeiras que se apresentam nas diferentes instâncias, não fazem parte da cultura política a discussão e priorização na área de esporte e lazer. As políticas esportivas e as vivências de lazer, apesar de serem direitos constitucionais e fazerem parte da vida cotidiana do cidadão, não têm a necessária atenção 
dos fóruns de políticas públicas, como tem as políticas de educação, saúde, habitação, segurança etc.

Sem dúvida esse é um dos maiores desafios das gestões municipais no planejamento e execução de suas políticas de esporte e lazer. A falta de legitimidade do lazer e delimitação de sua área de atuação, conforme já exposto anteriormente, aliada a uma constante escassez de recursos orçamentários, bem como pela falta de um planejamento bem definido e de metas claras de ação, formam a atual situação de muitas gestões municipais.

Para Saldanha Filho (2003), a tarefa do Estado em desenvolver o lazer e o esporte se viabiliza prioritariamente através do planejamento e execução de políticas públicas, as quais, quando consolidadas a partir de concepções e diretrizes claras, constituem elementos importantes para a materialização nas administrações públicas de gestões de políticas que garantam as condições necessárias para atender às demandas na área, de modo a implementá-los efetivamente como direitos do cidadão. Além do mais, é dever do Estado, e mais especificamente do município, promover a democratização das oportunidades de acesso às práticas de esporte e lazer nos espaços públicos que a tanto são destinados.

A questão do espaço público de lazer, nesse sentido, pode ser colocada no âmbito municipal como um dos pilares para a construção de uma política de lazer eficaz, que se dá a partir da articulação de diversas esferas e interesses que permeiam as relações políticas, mercadológicas e sociais no contexto urbano, com ênfase no resgate da funcionalidade do espaço público de lazer da cidade como componente da qualidade de vida.

Investigar o lazer no espaço urbano e a relação de seus espaços públicos com a qualidade de vida possibilita ampliar a discussão na área e contribuir para o direcionamento 
de políticas públicas e ações de planejamento no campo do lazer, principalmente pelas potencialidades que a construção de indicadores enseja no conhecimento da realidade social e possibilidade de maior articulação com outras áreas.

Pela centralidade que o espaço de lazer ocupa na discussão de suas políticas e por ser parte integrante das experiências e atividades de lazer, sendo o meio pelo qual elas acontecem, não só as categorias de trabalho e tempo irão influenciar o lazer, mas também, o espaço passa a se constituir como uma categoria imprescindível. Para Marcellino (2006, p.66), o essencial dessa discussão é compreender que "democratizar o lazer implica democratizar o espaço", de modo que "[...] ao tempo disponível corresponda um espaço disponível. E se a questão for colocada em termos da vida diária da maioria da população, não há como fugir do fato: o espaço para o lazer é o espaço urbano. As cidades são os grandes espaços e equipamentos de lazer".

Porém, quando se insere o lazer como um direito no espaço urbano, os problemas se intensificam. Existem muitas barreiras que dificultam o acesso ao lazer. A lógica do mercado dita quem pode ter acesso ao lazer, que hoje é visto mais como uma mercadoria, um "bem" individual a ser consumido por quem tem dinheiro, do que como um direito coletivo. Essa situação é vista com clareza por Gomes (2006, p.179), ao afirmar que "o lazer se mescla com o consumo e, aos direitos de cidadania, se sobrepõem os direitos de consumidor". É difícil encontrar nas cidades opções de lazer que não envolvam gastos substanciais, além das muitas dificuldades para acessá-las.

A maioria das cidades possui um número insuficiente de locais públicos para o lazer no atendimento à população. Além da evidente falta de espaços públicos específicos para o lazer, esses espaços, quando existentes, passam por outros problemas no âmbito urbano, 
tais como sua má distribuição pelas diferentes regiões da cidade; sua utilização, manutenção e conservação; a concorrência com os empreendimentos da iniciativa privada e o predomínio do lazer como mercadoria, movido pela lógica do capital e por um consumismo desenfreado.

Com relação à má distribuição desses equipamentos específicos na cidade, Gomes (2006, p.74) afirma que "a tensão entre público e privado interfere, necessariamente, no trato com o espaço urbano e, consequentemente, no trato com o espaço de lazer", o que compromete o acesso da população a bens de consumo coletivo e prejudica a qualidade de vida em interface com o lazer em diferentes regiões da cidade.

Ao aprofundar a análise no espaço público de lazer nas cidades, vê-se que as possibilidades de acesso ao mesmo muitas vezes é hierarquizada e privatizada, sendo recorrente no meio urbano, a existência de espaços públicos de lazer privilegiados, destinados a uma minoria ligada às elites, localizados em bairros cuja população possui maior poder aquisitivo. Por outro lado, é evidente a escassez de espaços e equipamentos públicos de lazer de qualidade nas periferias pobres. Além disso, a concorrência desigual que o espaço privado de lazer impõe sobre o espaço público, acaba por levar esse último a um processo de deterioração e abandono cada vez maior.

Desse modo, tem-se de um lado a cidade dividida em zonas ricas, com desenho urbanístico e localizações privilegiadas, com atenção constante do poder público e concentração de benefícios e equipamentos culturais e esportivos; do outro lado, bem distante, encontram-se subúrbios e periferias, carentes de infraestrutura, de recursos, de serviços e de equipamentos, visivelmente abandonados, fragmentados e desgastados. Para Melo e Alves Júnior (2003), existem duas cidades dentro de uma única, na qual uma parte 
da população usufrui de todas as benesses e a outra fica afastada de tudo e só participa da cidade quando se coloca como força de trabalho a serviço da primeira.

Além disso, Castellani Filho (2006, p.125) considera que o lazer, mais recentemente, inserido na lógica da sociedade de consumo como um "tempo e espaço de fruição dos interesses da indústria do entretenimento", restringe seu acesso somente àqueles portadores de condições socioeconômicas que possibilitem sua aquisição. O que é valorizado no lazer cotidiano não são atividades populares que fomentam o encontro, o convívio, a discussão, a participação etc., mas aquelas que possibilitam o consumo de diversas mercadorias, dentre elas, as manifestações culturais e esportivas desenvolvidas naqueles espaços em que o direito ao lazer é substituído pelo ato de consumir.

No mesmo contexto, Mascarenhas (2004), ao expor a desintegração do direito ao lazer, coloca que o problema do direito de consumidor se sobrepor aos chamados direitos de cidadania leva o lazer a se manifestar como objeto de conquista no mercado.

Os bens e serviços de lazer tornam-se acessíveis apenas para uma minoria, apresentando-se como um tipo muito específico de propriedade. Somente de posse desse 'direito', adquirido numa relação de compra e venda efetuada no mercado, nem sempre de modo direto, que o cidadãoconsumidor, como 'proprietário', pode valer-se do direito ao consumo, usufruindo, desfrutando, fruindo ou gozando de um determinado complexo de experiências lúdicas proporcionadas por aquilo que doravante convencionaremos chamar por 'mercolazer', forma contemporânea e tendencial de manifestação do lazer como mercadoria (MASCARENHAS, 2004, p.8).

Nessa perspectiva, é cada vez mais visível nas cidades a falta de espaços públicos para o lazer e o predomínio da oferta de espaços e equipamentos para o lazer mercadoria. Marcellino (2007, p.19) complementa esse pensamento ao dizer que "se o lazer é colocado 
pela sociedade capitalista enquanto um momento de consumo, o espaço para o lazer também é visto como um espaço para o consumo", seguindo uma tendência que leva à privatização de seus equipamentos, espaços de convívio e áreas verdes.

A sobrevivência de espaços públicos destinados ao lazer irá depender, então, diretamente da ação do poder municipal em reconhecer sua importância e promover sua ocupação pelas comunidades, principalmente das populações mais pobres, para que uma apropriação do espaço diferente possa acontecer. Também, depende da própria relação que a comunidade já estabelece com os mesmos ou por meio das lutas e organização política mobilizadas para sua implementação. Restringir o lazer à dimensão privada é desistir de promover uma cidade mais justa e humana.

Na busca pela consolidação do direito à cidade, e consequentemente, do direito ao lazer, a cidade deve ser pensada dentro de uma dimensão ampla e humana, que, para além da sua materialidade física, se corporifica em seus próprios cidadãos e nas relações sociais que acontecem em seu espaço cotidiano, buscando fazer com que a cidadania de fato faça parte da cidade.

Integrado a questões ligadas a trabalho, educação, saúde, habitação, infraestrutura urbana, transporte, entre outras, o lazer e sua política extrapolam a mera execução de atividades. Especificamente com relação a seus espaços públicos, a política de lazer passa a buscar um diálogo com outras áreas, estando diretamente relacionada à questão urbana do uso do solo, à construção e otimização dos equipamentos destinados a sua prática e ao uso desses espaços enquanto locais de interesse coletivo.

Nessa discussão, o tema do lazer se insere no âmbito das políticas urbanas, realçando a necessidade de uma política de investimento dirigida para superar a falta de 
espaços e de políticas públicas para sua ocupação, que se legitima, principalmente, quando o espaço de lazer se caracteriza como "espaço de encontro, convívio, do encontro com o ‘novo' e com o diferente, lugar de práticas culturais, de criação, de transformação e de vivências diversas, no que diz respeito a valores, conhecimentos e experiências (GOMES, 2006, p.73).

Espaços públicos como praças, quadras esportivas ou parques urbanos podem ser fundamentais para combater a mercadorização do lazer no ambiente urbano. Embora presente nas cidades brasileiras, esses espaços têm passado cada vez mais despercebidos e abandonados, tanto pelo Poder Público quanto pela própria comunidade, vítimas do descaso, do vandalismo, da falta de segurança e da violência.

Vinculado à esfera da vida, de seus valores humanos e de suas potencialidades sociais, o lazer e seus espaços públicos são essenciais para o desenvolvimento de uma maior qualidade de vida, sobretudo na relação com sua dimensão coletiva, da liberdade e da participação política (MORAIS, 1999; LINHALES, 1999). Nessa direção, as políticas de lazer devem se preocupar não só com a criação e manutenção de espaços públicos, mas também, em viabilizar atividades que possam envolver a comunidade e facilitar o seu acesso.

Dumazedier (1974, p.170-1) define o espaço de lazer, então, como um espaço social no qual acontecem relações específicas entre seres, grupos, meios e classes. Para ele:

[...] este espaço é determinado pelas características da população que o utiliza, pelo modo de vida dos diferentes meios sociais que o frequentam. Deverá ao mesmo tempo respeitar, desenvolver as diversidades culturais destes indivíduos para escapar à uniformização, à padronização, ao tédio social. Deverá também reduzir as diferenças, as disparidades, os 
desequilíbrios culturais que privam algumas esferas sociais de tudo o que a cultura urbana poderia lhes proporcionar.

A partir do momento em que o espaço público de lazer é incorporado na experiência cotidiana do indivíduo e adquire um significado, a apropriação desse bem comum público passa a não ser tarefa exclusiva do Poder Público, mas se expande para toda a comunidade, que também se sente responsável por ocupar e cuidar desse espaço. E, para que esse espaço possa ser, de fato, apropriado pela comunidade, ele deve ser, desde o seu processo de planejamento, discutido com a população que pretende atender para que suas aspirações e necessidades sejam respeitadas.

Assim, para se buscar a democratização do lazer na cidade, é fundamental que se envolva o poder público municipal e a comunidade. Gomes (2006, p.181-2) complementa essa realidade dizendo que é possível, por meio de ações e inserções mais comprometidas com a construção de uma nova sociedade, mais justa, solidária e humana, buscar "humanizar" a cidade. Para ela, a cidade, em vez de ser orientada apenas pelo desempenho do trabalho, necessita "expandir as possibilidades para que o lazer possa ser usufruído por todos os seus habitantes, com dignidade e criticidade, valorizando o ser humano que a constitui ao mesmo tempo em que é constituído". A autora ainda diz que o lazer pode deixar de ser restrito a um consumo alienado, para se transformar de fato em uma prática social que representa uma das dimensões da vida em sociedade.

Com isso, instrumentos que auxiliem a democratização do lazer no espaço urbano devem ser constantemente buscados para que a ampliação de espaços e condições disponíveis possibilite o aumento da prática de atividades, e sua ocupação possa ocorrer de forma consciente e participativa, potencializando as experiências no âmbito do esporte e 
lazer na cidade. Certamente, nessa perspectiva, o debate da qualidade de vida urbana tem muito a contribuir.

Para concluir, Pellegrin (2004, p. 72) expõe que a discussão do espaço de lazer e de seus equipamentos na cidade pode ser assim definida:

[...] os equipamentos de lazer fazem parte do desenho da cidade moderna, isto é, são formas urbanas concretas sobre as quais operam forças de ordem econômica e política. Dessa maneira, ao mapear uma cidade e os equipamentos de lazer que nela existem, contrastes urbanos diversos se fazem claros aos nossos olhos: áreas nas quais os equipamentos são abundantes, variados e bem conservados e áreas nas quais eles são raros, mal conservados, áreas de fácil acesso e áreas de difícil acesso, equipamentos superlotados e equipamentos subutilizados. Enfim, há vários contrastes possíveis de ser percebidos e que revelam que: 1) a lógica do capital se estende também sobre a distribuição dos equipamentos urbanos em geral, inclusive os de lazer [...]; 2) a rede urbana de equipamentos de lazer opera estreitamente ligada à dinâmica das outras redes de equipamentos, de transporte, habitação, etc., o que deve ser levado em conta pela Administração Pública ao desenvolver o planejamento urbano.

Aprofundar o conhecimento da realidade do lazer nas cidades é fundamental para o seu desenvolvimento enquanto área da qualidade de vida e muitos sistemas de indicadores de qualidade de vida urbana têm procurado inseri-lo como uma das variáveis a serem pesquisadas, levando em consideração, principalmente, a distribuição de equipamentos culturais, de infraestrutura esportiva, de parques, de praças e outros, pelas cidades. Ao expor desigualdades intraurbanas, o levantamento de indicadores, também no campo do lazer, torna-se uma ferramenta valiosa para o direcionamento de políticas públicas específicas e para ações integradas de planejamento urbano, contribuindo para maior legitimidade do lazer nesse debate e de novas possibilidades para sua democratização. 


\section{Considerações Finais}

Para além da aplicabilidade empírica, a construção da qualidade de vida como um novo paradigma no direcionamento das ações de planejamento urbano é essencial para resgatar a dimensão social e a cidadania no contexto urbano, envolvendo o Poder Público, os gestores, as organizações sociais e a própria população na busca por melhores condições de vida no cotidiano urbano.

Pensar os novos direcionamentos da política urbana no país integrados a outras políticas públicas com base nesse paradigma amplia a compreensão do desenvolvimento social no âmbito urbano, o que significa orientar as ações para a promoção de cidades preocupadas com múltiplos aspectos que determinam a vida de seus habitantes, inclusive naqueles referentes ao lazer e das potencialidades que suas vivências ensejam em diferentes dimensões.

Nessa perspectiva, a preocupação com a qualidade de vida urbana e suas implicações no resgate do valor de uso do espaço urbano e do sentido social da propriedade e da cidade deve estar presente no direcionamento do planejamento urbano e das políticas públicas de todas as cidades que buscam, mesmo com dificuldades, promover um desenvolvimento urbano verdadeiramente humano, com ações orientadas para a população e a partir de suas demandas, bases para o processo de participação cidadã e gestão da própria cidade, no qual se possa proceder às mudanças sociais e espaciais tão necessárias no contexto brasileiro.

Para o campo do lazer, essa aproximação com o debate da qualidade de vida urbana abre novas possibilidades de reivindicação e legitimação de suas práticas e, principalmente, da importância do acesso a diferentes espaços e equipamentos para suas vivências, na busca 
por uma cidade com maiores oportunidades de lazer, o que certamente contribuirá para uma vida com mais qualidade para todos.

\section{REFERÊNCIAS}

ALLARDT, Erik. Having, Loving, Being: an alternative to the Swedish Modelo of Welfare Research. In: NUSSBAUM, Martha; SEN, Amartya (Org.) The Quality of Life. Oxford University Press: New York, 1993. p.88-94.

BRASIL, Constituição (1988). In: Constituição da República Federativa do Brasil: promulgada em 5 de outubro de 1988. Obra coletiva de autoria da Editora Saraiva. São Paulo: Saraiva, 2006.

BRASIL, Congresso Nacional. Lei n. 10.257 de 10 de julho de 2001(Estatuto da Cidade). Regulamenta os arts. 182 e 183 da Constituição Federal, estabelece diretrizes gerais da política urbana e dá outras providências. Disponível em: $<$ http//www.planalto.gov.br/CCIVIL/LEIS_2001/L10257.htm> Acesso em: 10 maio 2008.

BRASIL, Ministério do Esporte. I Conferência Nacional do Esporte. Brasília-DF, junho, 2004. Disponível em: <http://portal.esporte.gov.br/conferencianacional/default.jsp $>$. Acesso em: 25 set. 2004.

, Ministério do Esporte. II Conferência Nacional do Esporte. Brasília-DF, maio, 2006. Disponível em: <http://portal.esporte.gov.br/conferencianacional/default.jsp>. Acesso em: 20 set. 2007.

BRASIL. Ministério do Esporte. III Conferência Nacional do Esporte. Brasília-DF, junho, 2010. Disponível em: $<$ http://portal.esporte.gov.br/conferencianacional/default.jsp $>$. Acesso em: 26 set. 2010.

BELO HORIZONTE. Secretaria de Planejamento/Indicadores. Disponível em: < http://portalpbh.pbh.gov.br/pbh/ >. Último acesso em: Janeiro, 2010.

BOGOTÁ COMO VAMOS. Colômbia. Disponível em: http://www.bogotacomovamos.org . Acesso em 15 jan. 2010.

BONALUME, Cláudia. O lazer numa proposta de desenvolvimento voltada à qualidade de vida. In: MÜLLER, Ademir; DA COSTA, Lamartine. Lazer e desenvolvimento regional. Santa Cruz do Sul, SC: EDNISC, 2002. p. 187- 212. 
CASTELLANI FILHO, Lino. Lazer e Qualidade de Vida. In: MARCELLINO, Nelson. (org.) Políticas Públicas Setoriais de Lazer: o papel das prefeituras. Campinas, SP: Autores Associados, 1996. p. 7- 21.

CASTELLANI FILHO, Lino. Gestão Municipal e política de lazer. In: YSAYAMA, Helder; LINHALES, Meily. (Orgs.) Sobre lazer e política: maneiras de ver, maneiras de fazer. Belo Horizonte: Editora UFMG, 2006. p.119-135.

CASTELlS, Manuel. A questão urbana. Tradução de Arlene Caetano. Rio de Janeiro: Paz e Terra, 2006 (1972). 590 p.

DUMAZEDIER, Joffre. Sociologia Empírica do Lazer. São Paulo: Editora Perspectiva, 1974. $244 \mathrm{p}$.

GLOBAL CITY INDICATORS. Indicadores Urbanos Globais: Uma Abordagem Integrada para a Mensuração e Monitoramento do Desempenho das Cidades. 2002. Disponível em: < <ttp://cityindicators.org> . Último acesso em: 25 jan. 2010.

GOMES, Christianne. Lazer, trabalho e qualidade de vida. In: CONGRESO DE EDUCACIÓN FÍSICA E CIENCIAS DO DEPORTE DOS PAÍSES DE LÍNGUA PORTUGUESA, 6., 1998, A Coruña. Deporte e Humanismo en Clave de Futuro. Anais... A Coruña: Universidade da Coruña, 1998 (não paginado).

GOMES, Christianne. Lazer - Concepções. In: GOMES, Christianne Luce (org.). Dicionário Crítico do Lazer. Belo Horizonte: Autêntica, 2004. p.119-125.

GOMES, Christianne. Lazer e Cidade: reflexões. In: As Cidades da Cidade. Carlos Antônio Leite Brandão (org.) Belo Horizonte: Ed. UFMG, 2006. p. 171-184.

HERCULANO, Selene. A qualidade de vida e seus indicadores. In: Revista Ambiente e Sociedade, Campinas, UNICAMP/NEPAM, Ano I, n. 2, $1^{\circ}$ semestre de 1998. p.01-24.

LEFÈBVRE, Henri. Espaço e Política. Belo Horizonte: Editora UFMG, 2008 (1972). 192 p.

LINHALES, Meily. Lazer, Cidadania e Qualidade de Vida - Reflexões acerca da possibilidade da Liberdade e da Ação Política. In: Licere. v.2, n.1, abril, 1999. Disponível em: https://seer.ufmg.br/index.php/licere/article/view/3967 . Acesso em: 02 dez. 2018.

LINHALES, Meily et al. Esporte e Lazer na Grande-BH: por onde caminham as gestões públicas. In: LINHALES, Meily; ISAYAMA, Hélder (Orgs.).Avaliação de políticas e políticas de avaliação: questões para o esporte e o lazer. Belo Horizonte: Editora UFMA, 2008. p. 13-57.

LOJKINE, Jean. O Estado capitalista e a questão urbana. 2. ed. São Paulo: Martins Fontes, 1997. 360 p. 
MAGNANI, José. Festa no Pedaço: cultura popular e lazer na cidade. 3.ed. São Paulo: Hucitec/UNESP, 2003. 192 p.

MARCELLINO, Nelson. Subsídios para uma política de lazer: o papel da Administração Municipal. In: (Org.). Políticas públicas setoriais de lazer: o papel das Prefeituras. Campinas, SP: Autores Associados, 1996. p.23- 30.

, O lazer e os espaços na cidade. In: ISAYAMA, Helder; LINHALES, Meily (Orgs.) Sobre lazer e política: maneiras de ver, maneiras de fazer. Belo Horizonte: Editora UFMG, 2006. p. 65-92.

MARCELLINO, Nelson et al. Introdução. In: Espaços e equipamentos de lazer em região metropolitana: o caso da RMC - Região Metropolitana de Campinas. Curitiba: Opus, 2007. p.10-28.

MARQUES, Renato. Esporte e Qualidade de Vida: reflexão sociológica. 2007. 160f. Dissertação (Mestrado em Educação Física) - Faculdade de Educação Física. Universidade Estadual de Campinas, Campinas, 2007.

MASCARENHAS, Fernando. Lazer e grupos sociais: concepções e método. 2000. $122 \mathrm{f}$. Dissertação (Mestrado), Faculdade de Educação Física, Universidade Estadual de Campinas, 2000.2 Disponível em: $<\mathrm{http}: / /$ cutter.unicamp.br/document/?code=vtls000213344\&fd=y $>$. Acesso em: 15 ago. 2008.

MASCARENHAS, Fernando. "Lazerania" também é conquista: tendências e desafios na era do mercado. In: MOVIMENTO, Porto Alegre, v. 10, n. 2, p. 73-90, maio/ago. 2004. Disponível em: http://boletimef.org/?canal=12\&file=897 . Acesso em: 10 jan. 2008.

MELO, Victor; ALVES JUNIOR, Edmundo. Introdução ao Lazer. Barueri, SP: Manole, 2003.

MORAIS, Patrícia. Lazer - Qualidade de Vida e Cidadania. In: Licere. v.2, n.1, abril, 1999. Disponível em: https://seer.ufmg.br/index.php/licere/article/view/3968 . Acesso em 2 dez. 2018.

MUNHOZ, Virna. O lazer como direito social na Prefeitura de Belo Horizonte. In: LINHALES, Meily; ISAYAMA, Hélder (Orgs.).Avaliação de políticas e políticas de avaliação: questões para o esporte e o lazer. Belo Horizonte: Editora UFMA, 2008. p. 5999.

NAHAS, Maria. Indicadores Intra-Urbanos como instrumentos de gestão da qualidade de vida urbana em grandes cidades: uma discussão teórico-metodológica. In: VITTE, Claudete; KEINERT, Tânia(Orgs.) Qualidade de Vida, Planejamento e Gestão Urbana: discussões teórico-metodológicas. Rio de Janeiro, Bertrand Brasil, 2009. p.123-153. 
NAHAS, Markus. Atividade física, saúde e qualidade de vida: conceitos e sugestões para um Estilo de Vida Ativo. 4.ed. Londrina: Midiograf, 2006. 282 p.

NAVARRO, Vera Lucia. Trabalho, saúde e tempo livre sob os domínios do capital. In: PADILHA, Walkíria (Org.). Dialética do Lazer. São Paulo: Cortez, 2006.p.50-74.

OLIVEIRA, Lucimara; MASCARÓ, Juan. Análise da qualidade de vida urbana sob a ótima dos espaços públicos de lazer. In: Ambiente Construído, Porto Alegre, v.7,n2, p.59-69, abr.jun. 2007. ISSN 1678-8621. Disponível em: https://seer.ufrgs.br/ambienteconstruido/article/viewFile/3737/2090 Acesso em: 30 out.2016.

ORGANIZAÇÃO DAS NAÇÕES UNIDAS (ONU). Declaração dos Direitos Humanos. 1948.

PADILHA, Walkíria. Introdução. In: (Org.). Dialética do Lazer. São Paulo: Cortez, 2006. p.9-18.

PELlEGRIN, Ana. Equipamento de Lazer. In: GOMES, Christianne Luce (Org.). Dicionário Crítico do Lazer. Belo Horizonte: Autêntica, 2004. p.69-73.

PORTO. Câmara Municipal. Sistema de Monitorização de Qualidade de Vida Urbana. Disponível em: <http://www.cm-porto.pt/gen.pl?sid=cmp.sections/915>. Acesso em: 15 jan. 2010.

REDE NOSSA SÃO PAULO. Quem somos. Disponível em: $<$ http://www.nossasaopaulo.org.br/portal> . Acesso em: 20 jan. 2010.

SALDANHA FILHO, Matheus. Formulando políticas públicas do esporte e lazer no âmbito da cidade. In: CONGRESSO BRASILEIRO DE CIÊNCIAS DO ESPORTE, 13., 2003, Caxambu. 25 anos de história: o percurso do CBCE na educação física brasileira. Anais... Caxambu: Colégio Brasileiro de Ciências do Esporte, 2003. Disponível em: $<$ http://boletimef.org/?canal=12\&file $=880>$. Acesso em: 10 jan. 2008.

SANTANA, Marco. Memória, cidade e cidadania. In: COSTA, I.; GONDAR, J. (Orgs.). Memória e Espaço. Rio de Janeiro, 7Letras, 2000. p. 44-53.

SEN, Amartya. Capability and Well-Being. In: NUSSBAUM, Martha; SEN, Amartya (Orgs.) The Quality of Life. Oxford University Press: New York, 1993. p. 30-53.

SILVA, Kelson. Lazer, espaço público e qualidade de vida na capital Potiguar - ensaio exploratório. Turismo: Estudos e Práticas - UERN, Mossoró/RN, vol.1, n.2, p. 48-60, jul./dez. $2012 \quad$ [ISSN 2316-1493]. Disponível em: http://periodicos.uern.br/index.php/turismo. Acesso em: 30 out. 2016. 
SILVA, Emília et al. Espaços públicos de lazer na promoção da qualidade de vida: uma revisão integrativa. Licere. v. 16, n.2, junho. 2013. p. 1-18. Disponível em: https://seer.ufmg.br/index.php/licere/article/view/372 . Acesso em: 02 dez. 2018.

SOUZA, Marcelo. Mudar a cidade: uma introdução crítica ao planejamento e à gestão urbanos. 5.ed. Rio de Janeiro: Bertrand, 2008. 560 p.

THE QUALITY OF LIFE PROJECT. Nova Zelândia. Disponível em: $<$ http://www.bigcities.govt.nz/index.htm> . Acesso em: 15 jan. 2010.

VÉRAS, Maura. Trocando Olhares: uma introdução à construção sociológica da cidade. São Paulo: Studio Nobel: EDUC, 2000. 117 p.

VILARTA, Roberto (Org.). Qualidade de Vida e Políticas Públicas: saúde, lazer e atividade física. Campinas, SP: IPPS Editorial, 2004. 154p.

VITTE, Claudete. Planejamento urbano, sustentabilidade urbana e qualidade de vida: considerações sobre o significado de cidade e de cidadania no início do século XXI. In: KEINERT, Tânia; KARRUZ, Ana Paula (Orgs.) Qualidade de Vida: observatórios, experiências e metodologias. São Paulo: Annablume: Fapesp, 2002. p.21- 38.

VITTE, Claudete. A qualidade de vida urbana e sua dimensão subjetiva: uma contribuição ao debate sobre políticas públicas e sobre a cidade. In: VITTE, Claudete; KEINERT, Tânia(Orgs.) Qualidade de Vida, Planejamento e Gestão Urbana: discussões teóricometodológicas. Rio de Janeiro, Bertrand Brasil, 2009. p.89-110.

VITTE, Claudete; KEINERT, Tânia. Apresentação. In: (Orgs.) Qualidade de Vida, Planejamento e Gestão Urbana: discussões teórico-metodológicas. Rio de Janeiro, Bertrand Brasil, 2009. p. 09-11.

YUAN, Lim; YUEN, Belinda; LOW, Christine. Quality of life in cities - Definition , Approches and Research. In : , Urban Quality of Life: critical issues and options. Singapura, National University of Singapore, 1999. p.01- 12.

\section{Endereço da Autora:}

Isabela Veloso Lopes Versiani UNIMONTES

Av. Prof. Rui Braga, S/N - Vila Mauriceia

Montes Claros - MG - 39.401-089

Endereço Eletrônico: isabelamoc@yahoo.com.br 